\title{
The Ethics and Legality of Using Personal Smartphones to take Medical Photographs
}

\author{
Amal A. Al Balushi
}

\section{أخحاقيات وقانونية استخدام المواتف الذكية الشخصية لالتقاط الصور الطبية}

$$
\text { أمل أحمد البلوشية }
$$

ABSTRACT: Photography in the medical profession is an asset that may help during patients' follow-up, monitoring the progression of diseases, getting a second opinion and in medical educational activities. Advances in technology, specifically smartphones, have enabled medical professionals to obtain high-quality photographs with minimal effort and photography experience. This article discusses the ethics and legality of using personal smartphones in a medical professional setting for medical photography. Written informed consent should always be obtained from the patient and should include details about how the photographs will be used.

Keywords: Photography; Smartphone; Informed Consent; Ethics; Medical Legislation; Publications; Medical Education; Oman.

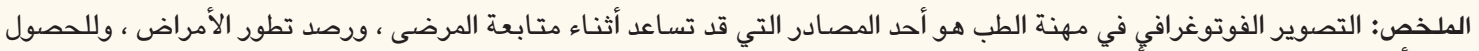

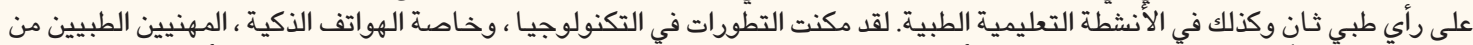

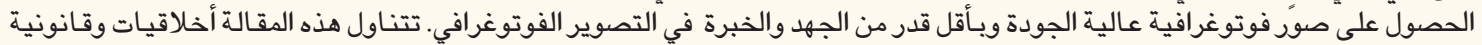

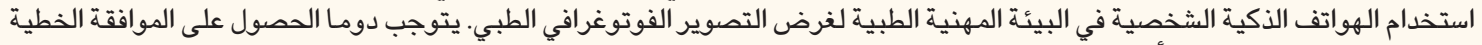

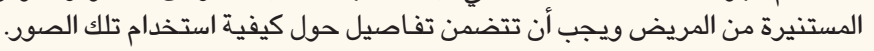

$$
\begin{aligned}
& \text { الكلمات المفتاحية: تصوير فوتوغرافي؛ هاتف ذكي؛ موافقة مستنيرة؛ أخلاقيات؛ تشريعات طبية؛ منشورات؛ تعليم طبي؛ عمان. }
\end{aligned}
$$

$\mathrm{N}$

OWADAYS, SMARTPHONES AND OTHER electronic devices are used everywhere. These devices continually advance and have rapidly developed over recent years to allow people to perform many functions with minimum effort, such as professional photography. This technology has provided healthcare workers with the ability to take high quality photographs that are automatically stored electronically on userfriendly devices at a low cost. ${ }^{1}$

Medical photographs are important in the management and follow-up of medical conditions, especially in visually oriented specialities such as dermatology and plastic surgery. ${ }^{2}$ These images are also used for teaching, research and publication purposes in addition to getting a second opinion from colleagues or consultants in the same or other specialities. ${ }^{3,4}$

In Oman, Article 332 of the Royal Decree 7/2018 is concerned with the photography of individuals without their consent; however, this law is not explicit for medical photography. ${ }^{5}$ In other jurisdictions, there are guidelines that regulate the practice of medical photography. ${ }^{6,7}$ Guidelines on this topic should address five main areas - consent, storage, retention, audit and transmission. ${ }^{8}$

\section{Case Scenario}

The following is a fictitious case scenario to exemplify the ethical and legal dilemmas of using personal smartphones to take medical photographs.

A 45-year-old female patient was referred to a plastic surgeon for an abdominoplasty after a sleeve gastrectomy had led to the patient losing $80 \mathrm{~kg}$ post-operatively in the first year. She complained of debilitating extra skin all over her body that was affecting her socially and in her daily life. Her surgeon reviewed her case and decided on multiple procedures, beginning with an abdominoplasty. The surgeon explained the procedure to her and the patient consented. During a pre-operative visit, the surgeon asked permission for medical photograph to be taken of her but she politely refused as she would have to expose herself to the male hospital photographer. Inside the operating room and before starting the surgery, the surgeon repeated the request for photographs to be taken by him to compare with the post-operative photographs. The patient hesitated but then agreed. He covered her genital area and took photographs with his personal smartphone. 
One month later, an anxious patient presented at the surgeon's clinic for the same procedure. The surgeon explained the procedure to her and answered her questions. In an attempt to ease her anxiety, he showed her the preand post-operative photographs of his previous patient from his personal smartphone. The new patient agreed to have the procedure.

\section{Discussion}

Chan et al. found that in Canada, 89\% of surveyed surgeons and residents have taken medical photographs using smartphone devices. ${ }^{9}$ In Australia, Abbott et al. reported that smartphones were used for sending and receiving images by $50 \%$ of Australian dermatology residents and specialists and that these medical photographs were electronically stored with limited privacy and security settings. ${ }^{10}$

The use of smartphones in hospitals can aid in speeding-up specialist consultations, for example, Muir et al.'s study revealed that emergency departments received dermatology consultations within two hours by using smartphones. ${ }^{11}$ The use of smartphones has also improved triaging and management of inpatient dermatology consultations. ${ }^{12-14}$

Written informed consent should be obtained before taking medical photographs despite this taking more time, to avoid future medical litigation; ${ }^{5}$ verbal consent is insufficient. Failure to obtain informed consent is a breach of article 3 of the Human Rights Act. ${ }^{15}$ The article states that "No one shall be subjected to torture or to inhuman or degrading treatment or punishment". 16 In addition, taking medical photographs of non-consenting patients is a breach of the patient's privacy. It might be argued that a patient consents by default if a photograph is taken and no objection was raised. However, this is not the case when taking intra-operative photographs on anaesthetised patients. Even in the case of a rare condition which is discovered intra-operatively, a photograph should not be taken without prior consent. If such a discovery is anticipated, written consent mentioning intra-operative photography and highlighting the image's future uses, should be sought. Importantly, patients need to understand their right to refuse as some might assume having pictures taken is necessary to their care.

Personal smartphones should never be used to take medical photographs. This risks violating the privacy and confidentiality of the patient. Personal smartphones are not only used at work but also at home and in public places. Therefore, there is a risk that doctor-patient confidentiality may be breached if a patient's images are revealed during for example, a social interaction wherein personal photographs are being shown to others.

Kunde et al. urge physicians to help ensure the privacy of patient's photographs on personal devices by enabling additional security features such as security codes. ${ }^{4}$ They present a scenario where a physician's smartphone was stolen and patient's images were uploaded onto the internet. ${ }^{4}$ It was the physician's responsibility to maintain the confidentiality of his patient's images, yet he failed by not securely storing them. However, enabling security features on personal devices may not be enough as smartphones can be breached. It is preferable to use a camera connected to the hospital computer system so that the patient's image can be stored in the patient's electronic file which typically has a better security system than a smartphone. If the security of the electronic filing system is questionable, photographs should not be taken.

Individuals who require or seek medical attention are dependent on their doctor for medical expertise and this makes the patients vulnerable. ${ }^{17,18}$ This imbalance of power can influence patients to agree to have their photograph taken when they would otherwise refuse.

Physicians must not exaggerate or overestimate the need for a photograph. A physician's request for photography might be difficult to refuse especially if there is a trusting doctor-patient relationship as in the case scenario presented above. The patient might fear the loss of this relationship and the potential consequences of reduction in care quality or the possibility of finding an alternative physician. In order to avoid such a situation, consent can be requested via a third party who the patient is neutral towards and can therefore easily be refused without potentially compromising the doctor-patient relationship. This third party may be another member of the healthcare team or a trained nurse. The physician should highlight that a refusal to allow medical photographs to be taken will not affect the patient's care. Moreover, if a patient refuses medical photography, the physician must not repeat this request. Repetition of medical photography requests pressures the patient against his or her wishes resulting in invalidation of the consent.

Medical photographs taken without consent are categorised as either paternalistic practice (physician chooses to not act in the patient's best interest) or as ethical egoism (physician acts in their own interest regardless of the patient's best interest). ${ }^{19}$ Using medical photographs for follow-up or to seek a second opinion by sending it to a colleague is an example of the former, while using them for publication and teaching purposes without consent is an example of the latter. Both practices should not be exercised as non-consented medical photography is unethical and a potential source for litigation. 
Sometimes patients show a medical photograph containing transient, progressive or recurrent pathology to their doctor; implied consent is assumed for such images if shared for diagnostic purposes. ${ }^{5}$ However, if a physician requests a copy of the photograph, consent should be obtained. ${ }^{5}$ Photographs of non-identifiable radiographic investigations can be taken with verbal consent in addition to documenting the diagnostic and patient care purpose in the patient's file. ${ }^{20}$ Written consent is needed for educational and publication purposes of medical photographs of investigations as usually the patient's demographic data and their clinical presentation are shared.

\section{Recommendations}

Verbal patient consent is insufficient and, therefore, obtaining written informed consent should be standard practice before starting any treatment that requires medical photography. Obtaining informed consent is the physician's responsibility even if it is delegated to a member of staff. ${ }^{21}$ The physician should explain and discuss the purpose of the medical photography, its potential benefits to the patient and to the management of the patient's condition, as well as the associated risks and who will have access to the photographs; such information should be clearly stated in the informed consent form. Unintentional risk of disclosure of the patient's identity and confidentiality even with efforts to cover their identity such as covering eyes must be explained to the patient. ${ }^{21}$ Moreover, patient's should be allowed to choose the purpose of their medical photograph (e.g. to monitor the progression of the condition, for educational purposes or both) and any future use such as research, publication or educational uses should be clearly stated with an option to withdraw consent at any time. However, it is important for the physician to highlight that after dissemination of the photographs through publication or educational materials, it is impossible to withdraw consent or remove the photographs. ${ }^{21}$ Consent for photographs taken for clinical purposes can be withdrawn at any time and the photographs removed since they are securely stored in the patient's file. Theoretically, a patient's photographs are their property as long as they are solely in their clinical file, but once they are published publicly, they are no longer a patient's property and patients must be made aware of this.

A chaperone should be present during the photography process, especially if the patient and photographer/ physician are of different genders. ${ }^{22,23}$ The name of the chaperone or refusal of a chaperone needs to be documented in the consent form and clinical records. ${ }^{23}$ Moreover, exposure of the patient's body parts should be limited to where the disease/condition appears and the photograph should be shown to the patient for final approval.

Medical photography requests should not be repeated if the patient is reluctant or unwilling. Patients should be allowed to choose between a specialised medical photographer or the treating physician, especially if the involved area of the body is private. Medical photographs must only be stored in the hospital's computer system and deposited in the patient's file. Patient photographs should never be stored on personal devices and must not be taken outside hospital premises unless for educational purposes.

Ideally, personal smartphones should not be used for medical photography. However, if their use is necessary to communicate with consultants, the physician should obtain written informed consent after explaining the purpose and with whom the photograph will be shared and must be deleted after the consultation. This should be documented in the patient's file. ${ }^{5}$ Alternatively, allocated mobile devices for professional use only, that are synchronised with the hospital's computer system, can be used to receive consultations based on shared medical photographs even outside hospital premises.

\section{Conclusion}

Using smartphones for medical photography is faster, more convenient and widely available. However, ethical issues such as patient confidentiality and privacy may be breached when using smartphones to take patient photographs, especially when using personal devices. Therefore, it is recommended that only hospital equipment be used and written informed consent be obtained to avoid litigation/ethical misconduct.

\section{References}

1. Kornhaber R, Betihavas V, Baber RJ. Ethical implications of digital images for teaching and learning purposes: An integrative review. J Multidiscip Healthc 2015; 8:299-305. https://doi.org/10.2147/JM DH.S84488.

2. Mahar PD, Foley PA, Sheed-Finck A, Baker CS. Legal considerations of consent and privacy in the context of clinical photography in Australian medical practice. Med J Aust 2013; 198:48-9. https://doi.org/10.5694/mja12.11086.

3. Palacios-González C. The ethics of clinical photography and social media. Med Health Care Philos 2015; 18:63-70. https:// doi.org/10.1007/s11019-014-9580-y.

4. Kunde L, McMeniman E, Parker M. Clinical photography in dermatology: Ethical and medico-legal considerations in the age of digital and smartphone technology. Australas J Dermatol 2013; 54:192-7. https://doi.org/10.1111/ajd.12063.

5. Ministry of Legal Affairs. The Penal Law Promulgated by Royal Decree 7/2018. From http://www.mola.gov.om/Download.aspx? Path=PDF/Omani\%20Penal.pdf Accessed: Feb 2019. 
6. Institute of Medical Illustrators. IMI National Guidelines: Consent to Clinical Photography. From: http://www.imi.org.uk/file/ download/2143/IMINatGuidelinesConsentMarch_2007.pdf Accessed: Feb 2019.

7. The Royal Australian and New Zealand College of Ophthalmologists. Guidelines on Use of Clinical Photographs. From: https:// ranzco.edu/ArticleDocuments/176/Use\%20of\%20Clinical\%20 Photography\%20Guidelines.pdf.aspx?Embed=Y Accessed: Feb 2019 .

8. Heyns M, Steve A, Dumestre DO, Fraulin FO, Yeung JK. Canadian guidelines on smartphone clinical photography. Canadian J Physician Leadersh 2018; 4:158-63.

9. Chan N, Charette J, Dumestre DO, Fraulin FO. Should 'smart phones' be used for patient photography? Plast Surg (Oakv) 2016; 24:32-4. https://doi.org/10.1177/229255031602400109.

10. Abbott LM, Magnusson RS, Gibbs E, Smith SD. Smartphone use in dermatology for clinical photography and consultation: Current practice and the law. Australas J Dermatol 2018; 59:101-7. https://doi.org/10.1111/ajd.12583.

11. Muir J, Xu C, Paul S, Staib A, McNeill I, Singh P, et al. Incorporating teledermatology into emergency medicine. Emerg Med Australas 2011; 23:562-8. https://doi.org/10.1111/j.17426723.2011.01443.x

12. Duong TA, Cordoliani F, Julliard C, Bourrat E, Regnier S, de Pontual L, et al. Emergency department diagnosis and management of skin diseases with real-time teledermatologic expertise. JAMA Dermatol 2014; 150:743-7. https://doi.org/10.10 01/jamadermatol.2013.7792.

13. Barbieri JS, Nelson CA, James WD, Margolis DJ, Littman-Quinn R, Kovarik CL, et al. The reliability of teledermatology to triage inpatient dermatology consultations. JAMA Dermatol 2014; 150:419-24. https://doi.org/10.1001/jamadermatol.2013.9517.

14. Börve A, Holst A, Gente-Lidholm A, Molina-Martinez R, Paoli J. Use of the mobile phone multimedia messaging service for teledermatology. J Telemed Telecare 2012; 18:292-6. https:// doi.org/10.1258/jtt.2012.120206
15. Berle I. Clinical photography and patient rights: The need for orthopraxy. J Med Ethics 2008; 34:89-92. https://doi.org/10.11 36/jme.2006.019166

16. Human Rights Act 1998. Aritcle 3. From: https://www.legislation.gov.uk/ukpga/1998/42/schedule/1/part/I/chapter/2 Accessed: Feb 2019.

17. Matthews S, Tobin B. Human vulnerability in medical contexts. Theor Med Bioeth 2016; 37:1-7. https://doi.org/10.1007/s11017016-9357-9.

18. Berle I. The principles of ethical practice in professional clinical photography. J Audiov Media Med 2004; 27:11-13. https://doi. org/10.1080/01405110310001658897.

19. Berle I. The ethical context of clinical photography. J Audiov Media Med 2002; 25:106-9. https://doi.org/10.1080/01405110 2320376816 .

20. Heyns M, Steve A, Dumestre DO, Fraulin FO, Yeung JK. Best practices for smartphone and smart-device clinical photo taking and sharing. Canadian Medical Association. From: http://policybase.cma.ca/dbtw-wpd/Policypdf/PD18-04.pdf Accessed: Feb 2019.

21. Lakdawala N, Fontanella D, Grant-Kels JM. Ethical considerations in dermatologic photography. Clin Dermatol 2012; 30:486-91. https://doi.org/10.1016/j.clindermatol.2011.06.017.

22. Clynch, P. Chaperones within a sensitive medical photography environment. J Vis Commun Med 2009; 32:99-100. https://doi. org/10.3109/17453050903226000.

23. Saidun S. Photographing human subjects in biomedical disciplines: An Islamic perspective. J Med Ethics 2013; 39:84-8. https://doi.org/10.1136/medethics-2012-100794. 